\title{
The Utility of Epworth Sleepiness Scale to Screen Moderate and Severe Obstructive Sleep Apnea Preoperatively to Predict Difficult Airway
}

\author{
Rashmi Soori ${ }^{1}$ Ivor D'Sa² Giridhar Hosmane ${ }^{3}$ \\ ${ }^{1}$ Department of Anaesthesiology, K.S. Hegde Medical Academy, \\ Deralakatte, Mangaluru, Karnataka, India \\ ${ }^{2}$ Department of General Medicine, K.S. Hegde Medical Academy, \\ Deralakatte, Mangaluru, Karnataka, India \\ ${ }^{3}$ Department of Pulmonary Medicine, K.S. Hegde Medical Academy, \\ Deralakatte, Mangaluru, Karnataka, India
}

J Health Allied Sci ${ }^{\mathrm{Nu}: 2021 ; 11: 93-96}$

\author{
Address for correspondence Rashmi Soori, MD, PDCC, Department \\ of Anaesthesiology, K.S. Hegde Medical Academy, Deralakatte, \\ Mangaluru 575018, Karnataka, India \\ (e-mail:drrashmisoori@gmail.com).
}

\begin{abstract}
Keywords

- OSA

- preoperative

- questionnaire

Introduction Obstructive sleep apnea (OSA) is sleep-disordered breathing characterized by repetitive episodes of partial or complete upper airway collapse in sleep leading to apnea and/or hypopnea, desaturations, sleep disruptions, and cardiovascular changes. OSA is a known cause for difficult airway, especially mask ventilation. Daytime sleepiness is one of the hallmark symptoms of OSA. So, we used the Epworth sleepiness score (ESS) in patients suspected of OSA undergoing a sleep study.

Methods Overall, 44 subjects suspected to have OSA and undergoing polysomnography were included in the study. The socio-demographic details and the complaints were recorded and the Epworth sleepiness questionnaire was administered. The severity of OSA was graded as per the American Academy of Sleep Medicine using the apnea hypopnea index.

Results A total of 44 patients were included in the study. Out of these, 19 were mild, 13 moderate, and 12 severe OSA cases, respectively. ESS of more than 10 showed a positive predictive value of $81.25 \%$ and specificity of $85 \%$ in screening patients with moderate and severe OSA. But the sensitivity and negative predictive value was only 54.16 and $60.71 \%$, respectively.

Conclusion ESS being a simple questionnaire can be easily used preoperatively. A score of more than 10 effectively diagnoses moderate and severe OSA, but less than 10 cannot rule out OSA
\end{abstract}

\section{Introduction}

Obstructive sleep apnea (OSA) is sleep-disordered breathing characterized by repetitive episodes of partial or complete upper airway collapse in sleep leading to apnea and/ or hypopnea, desaturations, sleep disruptions, and cardiovascular changes. OSA is a known cause for difficult airway, especially mask ventilation, and is more prevalent in males, obese, elderly, craniofacial deformities, neuromuscular disorders, alcohol consumption, etc. ${ }^{1}$ Approximately $80 \%$ of OSA are undiagnosed and may pose serious challenges during induction and recovery due to the airway collapse.,3 Daytime sleepiness is one of the hallmark symptoms of OSA leading to various health hazards. Epworth sleepiness score (ESS) is an published online

January 26, 2021
DOI https://doi.org/

$10.1055 / \mathrm{s}-0041-1722823$ ISSN 2582-4287. (c) 2021. Nitte (Deemed to be University).

This is an open access article published by Thieme under the terms of the Creative Commons Attribution-NonDerivative-NonCommercial-License, permitting copying and reproduction so long as the original work is given appropriate credit. Contents may not be used for commercial purposes, or adapted, remixed, transformed or built upon. (https://creativecommons.org/licenses/by-nc-nd/4.0/). Thieme Medical and Scientific Publishers Pvt. Ltd. A-12, 2nd Floor, Sector 2, Noida-201301 UP, India 
objective way to grade daytime sleepiness. It is a questionnaire being administered to subjects and graded as per the points they have scored. A score of 10 and less is normal, 11 to 13 is mild daytime sleepiness, 14 to 15 is moderate daytime sleepiness, and 16 or more is severe daytime sleepiness. ${ }^{4}$ So, we used the ESS in patients suspected of OSA undergoing a sleep study.

\section{Methods}

After obtaining ethical committee clearance, we conducted this study in a tertiary care hospital. Overall, 44 subjects suspected to have OSA and undergoing polysomnography were included in the study. The socio-demographic details and the complaints were recorded and the Epworth sleepiness questionnaire ( - Table 1) was administered. ESS is a questionnaire consisting of eight questions each graded from 0 to 3 . The minimum score is 0 and the maximum score 24 . The patients were asked the questions and asked to grade their sleepiness for each scenario. In case the patient was unable to comprehend the questionnaire, they were excluded from the study. The subjects then underwent overnight polysomnography and the severity of OSA was graded as per the American Academy of Sleep Medicine using apnea hypopnea index (AHI).

The data were tabulated in an MS Excel sheet and demographic details and complaints are depicted as frequencies and percentages. Daytime sleepiness and severity of OSA are depicted as frequencies and percentages. ESS and AHI were correlated using Spearman's correlation. Body mass index

Table 1 Epworth sleepiness score

\begin{tabular}{|c|c|}
\hline Name: & $\begin{array}{l}\text { Today's } \\
\text { date: }\end{array}$ \\
\hline Your age $(y)$ : & Your sex: \\
\hline \multicolumn{2}{|c|}{$\begin{array}{l}\text { How likely are you to doze off or fall asleep in the following } \\
\text { situations, in contrast to feeling just tired? This refers to your } \\
\text { usual way of life in recent times. Even if you have not done some } \\
\text { of these things recently, try to work out how they would have } \\
\text { affected you. } \\
\text { Use the following scale to choose the most appropriate number for } \\
\text { each situation: } \\
0=\text { would never doze } \\
1=\text { slight chance of dozing } \\
2 \text { = moderate chance of dozing } \\
3=\text { high chance of dozing }\end{array}$} \\
\hline Situation & Score \\
\hline Sitting and reading & \\
\hline Watching TV & \\
\hline $\begin{array}{l}\text { Sitting, inactive in a public place (e.g., a theater } \\
\text { or a meeting) }\end{array}$ & \\
\hline $\begin{array}{l}\text { As a passenger in a car for an hour without a } \\
\text { break }\end{array}$ & \\
\hline $\begin{array}{l}\text { Lying down to rest in the afternoon when circum- } \\
\text { stances permit }\end{array}$ & \\
\hline Sitting and talking to someone & \\
\hline Sitting quietly after a lunch without alcohol & \\
\hline $\begin{array}{l}\text { In a car, while stopped for a few minutes in the } \\
\text { traffic }\end{array}$ & \\
\hline
\end{tabular}

(BMI) and ESS were correlated using Pearson's correlation. ESS with a score of more than 10 was used as a test to screen moderate and severe OSA.

\section{Results}

A total of 44 patients were included in the study. Out of these, 19 were mild, 13 moderate, and 12 severe OSA cases, respectively. Demographic details (-Table 2) and complaints ( - Table 3 ) show that $68.18 \%$ are males. The majority of them are in the age group 18 to 33 years followed by 48 to 63 years.

Table 2 Demographic data

\begin{tabular}{|c|c|c|c|}
\hline $\begin{array}{l}\text { Demographic } \\
\text { details }\end{array}$ & Group & Frequency & Percentage \\
\hline \multirow[t]{4}{*}{ Age } & $18-33 y$ & 16 & 36.36 \\
\hline & $33-48 y$ & 11 & 25 \\
\hline & $48-63 y$ & 15 & 34.09 \\
\hline & $63-78 y$ & 2 & 4.54 \\
\hline \multirow[t]{2}{*}{ Sex } & Males & 30 & 68.18 \\
\hline & Females & 14 & 31.81 \\
\hline \multirow[t]{4}{*}{ BMI $\left(\mathrm{kg} / \mathrm{m}^{2}\right)$} & $14.9-21$ & 11 & 25 \\
\hline & $21-27.1$ & 12 & 27.27 \\
\hline & $27.1-33.2$ & 12 & 27.27 \\
\hline & $33.2-39.3$ & 8 & 18.18 \\
\hline \multirow[t]{3}{*}{ OSA severity } & Mild & 19 & 43.18 \\
\hline & Moderate & 13 & 29.54 \\
\hline & Severe & 12 & 27.27 \\
\hline \multirow[t]{4}{*}{$\begin{array}{l}\text { Daytime } \\
\text { sleepiness }\end{array}$} & $\begin{array}{l}\text { Normal } \\
(\text { ESS } \leq 10)\end{array}$ & 28 & 63.63 \\
\hline & $\begin{array}{l}\text { Mild (ESS } \\
11-12 \text { ) }\end{array}$ & 10 & 22.72 \\
\hline & $\begin{array}{l}\text { Moderate } \\
\text { (ESS } \\
13-15)\end{array}$ & 4 & 9.09 \\
\hline & $\begin{array}{l}\text { Severe (ESS } \\
\geq 16 \text { ) }\end{array}$ & 2 & 4.54 \\
\hline
\end{tabular}

Abbreviations: BMI, body mass index; ESS, Epworth sleepiness score; OSA, obstructive sleep apnea.

Table 3 History of the subjects

\begin{tabular}{|l|l|l|}
\hline Complaints & Yes & No \\
\hline Snoring & 42 & 2 \\
\hline Positional variation of snoring & 13 & 31 \\
\hline Obstructive episodes & 25 & 19 \\
\hline Arousal/nocturnal choking & 24 & 20 \\
\hline Excessive daytime sleepiness & 32 & 12 \\
\hline Intellectual deterioration & 0 & 44 \\
\hline Personality changes & 8 & 36 \\
\hline Abnormal motor movements & 4 & 40 \\
\hline Morning headaches & 15 & 29 \\
\hline Nocturnal enuresis/impotence & 1 & 43 \\
\hline Nasal obstruction & 31 & 13 \\
\hline
\end{tabular}


Our findings showed that $50 \%$ of the severe OSA cases had an ESS of more than 13, that is moderate to severe daytime sleepiness, whereas the remaining $50 \%$ of the severe OSA cases had mild or normal daytime sleepiness. However, all the mild OSA cases had mild or normal daytime sleepiness. Further, in mild OSA, $80 \%$ of them had no daytime sleepiness whereas only $20 \%$ had mild daytime sleepiness.

The ESS of more than 10 showed a positive predictive value (PPV) of $81.25 \%$ and specificity of $85 \%$ in screening patients with moderate and severe OSA. But the sensitivity and negative predictive value (NPV) was only 54.16 and $60.71 \%$, respectively.

\section{Discussion}

OSA is one of the important causes of difficult mask ventilation and hence difficult airway. If suspected, it can lead to more preparedness in the form of keeping oral airway, laryngeal mask airway, and preferring faster-acting muscle relaxants like succinylcholine or rocuronium during the general anesthetic procedure. OSA patients are more sensitive to benzodiazepines and opioids precluding their use to a minimum. Also, they may pose a challenge in postoperative care due to the airway collapse during sleep and subsequent desaturations. So awake extubation should be done whenever possible. The nasopharyngeal airway may be helpful in case of upper airway collapse in the postoperative period. Hence preanesthetic evaluation with high suspicion in susceptible individuals is of paramount importance.

Our study showed that the majority of the diagnosed OSA were males (68.18\%) compared with females (31.8\%), which is similar to the study by Kapsimalis and Kryger showing that one-third of diagnosed OSA patients are females. ${ }^{5}$ Although sleep-disordered breathing is known to be more prevalent in the elderly, there were only 2 patients (4.54\%) between 63 and 78 years of age. ${ }^{6}$ This could be explained by the fact that the elderly, being concerned about other more severe health issues, do not seek help for sleep-disordered breathing and its consequence. Pearson's correlation coefficient between BMI and ESS is 0.190 (weak correlation) with a $p$-value of 0.222 (not significant). This is similar to the study by Dagan et al showing a poor correlation between higher BMI and subjective daytime sleepiness; however, they showed that there was a correlation between increased BMI and shorter sleep latency times. ${ }^{7}$

Although 32 patients were complaining of excessive daytime sleepiness, only 16 had daytime sleepiness as per ESS. This is similar to a study by Mediano et al, showing that the majority of patients with OSA complaining of excessive daytime sleepiness fail to show it as per ESS. ${ }^{8}$ Although the majority of studies have shown no correlation between ESS and AHI and Guo et al showed a strong correlation between weighted ESS and AHI, our study showed that Spearman's correlation coefficient between ESS and AHI is 0.54 (moderately correlated). ${ }^{9-13}$

Previous studies have shown that subjective daytime sleepiness scores cannot be used to screen OSA. ${ }^{10-12}$
Also, ESS cannot be used to screen OSA in subjects with a history of snoring. ${ }^{14}$ Mild OSA may not pose much risk perioperatively, but moderate and severe OSA are prone to airway-related complications. Hence, we used ESS with a score of more than 10 to screen moderate and severe OSA. This showed a PPV of $81.25 \%$ and specificity of $85 \%$, which means that ESS can be efficiently used as a screening modality perioperatively. All patients with ESS of more than 10 should be managed cautiously concerning airway-associated problems perioperatively. The sensitivity and NPV was only 54.16 and $60.71 \%$, respectively; hence some patients with moderate and severe OSA might have been missed while screening. These values are similar to other studies. ${ }^{15}$ Other corroborative features like history and physical examination along with the questionnaire may be used to pick these cases. A study by Senaratna et al opined that STOP-BANG, Berlin's questionnaire, and OSA50 questionnaire, along with ESS of more than or equal to 8 , can be used to rule in but not rule out clinically relevant OSA, similar to our results. ${ }^{16}$

The limitation of our study was that we included subjects with suspected OSA undergoing polysomnography and hence included all subjects with AHI of more than 5 , and none were less than 5 .

\section{Conclusion}

ESS being a simple questionnaire can be easily used preoperatively. A score of more than 10 effectively diagnoses moderate and severe OSA, but less than 10 cannot rule out OSA.

\section{Note}

This work was primarily carried out at K.S. Hegde Medical College.

\section{Conflict of Interest}

None declared.

\section{References}

1 Loadsman JA, Hillman DR. Anaesthesia and sleep apnoea. $\mathrm{Br}$ J Anaesth 2001;86(2):254-266

2 Singh M, Liao P, Kobah S, Wijeysundera DN, Shapiro C, Chung F. Proportion of surgical patients with undiagnosed obstructive sleep apnoea. Br J Anaesth 2013;110(4):629-636

3 Seguin L, Tamisier R, Deletombe B, Lopez M, Pepin JL, Payen JF. Preoperative screening for obstructive sleep apnea using alternative scoring models of the Sleep Tiredness Observed Pressure-Body Mass Index Age Neck Circumference Gender Questionnaire: an external validation. Anesth Analg 2020;131(4):1025-1031

4 Johns MW. A new method for measuring daytime sleepiness: the Epworth sleepiness scale. Sleep 1991;14(6):540-545

5 Kapsimalis F, Kryger MH. Gender and obstructive sleep apnea syndrome, part 1: clinical features. Sleep 2002;25(4):412-419

6 Kitakata H, Kohno T, Fukuda K. Sleep-disordered breathing in the elderly: is it distinct from that in the younger or middle-aged populations? J Thorac Dis 2018;10(Suppl 9):S1102-S1107

7 Dagan Y, Doljansky JT, Green A, Weiner A. Body mass index (BMI) as a first-line screening criterion for detection of 
excessive daytime sleepiness among professional drivers. Traffic Inj Prev 2006;7(1):44-48

8 Mediano O, Barceló A, de la Peña M, Gozal D, Agustí A, Barbé F. Daytime sleepiness and polysomnographic variables in sleep apnoea patients. Eur Respir J 2007;30(1):110-113

9 Belgü AU, Erdoğan B, San T, Gürkan E. The relationship between AHI, Epworth scores and sleep endoscopy in patients with OSAS. Eur Arch Otorhinolaryngol 2015;272(1):241-245

10 Guimarães C, Martins MV, Vaz Rodrigues L, Teixeira F, Moutinho Dos Santos J. Epworth Sleepiness Scale in obstructive sleep apnea syndrome-an underestimated subjective scale. Rev Port Pneumol 2012;18(6):267-271 (English Edition)

11 Sauter C, Asenbaum S, Popovic R, et al. Excessive daytime sleepiness in patients suffering from different levels of obstructive sleep apnoea syndrome. J Sleep Res 2000;9(3):293-301
12 Durán J, Esnaola S, Rubio R, Iztueta A. Obstructive sleep apnea-hypopnea and related clinical features in a population-based sample of subjects aged 30 to $70 \mathrm{yr}$. Am J Respir Crit Care Med 2001;163(3 Pt 1) :685-689

13 Guo Q Song WD, Li W, et al. Weighted Epworth sleepiness scale predicted the apnea-hypopnea index better. Respir Res 2020;21(1):147

14 Osman EZ, Osborne J, Hill PD, Lee BW. The Epworth Sleepiness Scale: can it be used for sleep apnoea screening among snorers? Clin Otolaryngol Allied Sci 1999;24(3):239-241

15 Dixit R, Verma S, Pawar KS. Screening for obstructive sleep apnea using Epworth sleepiness score and Berlin questionnaire: which is better? Indian J Respirat Care. 2018;7(1):33

16 Senaratna CV, Perret JL, Lowe A, et al. Detecting sleep apnoea syndrome in primary care with screening questionnaires and the Epworth sleepiness scale. Med J Aust 2019;211(2):65-70 